Article

\title{
Assessing the Impact of Photovoltaics on Rooftops and Facades in the Urban Micro-Climate
}

\author{
Miguel Centeno Brito $\mathbb{D}$ \\ Instituto Dom Luiz, Faculdade de Ciências da Universidade de Lisboa, Campo Grande, 1749-016 Lisbon, \\ Portugal; mcbrito@fc.ul.pt
}

Received: 20 April 2020; Accepted: 22 May 2020; Published: 28 May 2020

\begin{abstract}
This work addresses the potential impact of large-scale deployment of photovoltaics in the urban environment on the local micro-climate. A one- and two-dimensional steady-state irradiance balance model was developed to estimate the impact of changing the effective albedo of rooftops and facades fully covered with photovoltaic modules. Results show that, albeit small, with current PV conversion efficiencies, photovoltaics on rooftops are expected to have a heating effect on the urban environment. The effect of facades depends strongly on the reflective properties of the surroundings (e.g., road albedo) but it is always small (below $4 \%$ ), and, therefore, photovoltaics ought not to be considered a mitigation strategy for urban heat island.
\end{abstract}

Keywords: urban heat island; photovoltaics; facades

\section{Introduction}

The urban heat island (UHI) effect is a well-established phenomenon characterized by anthropogenic heating of an urban area when compared to its surrounding rural areas [1]. It leads to higher energy demand, and it has been associated with a significant impact on human health [2], in particular during heat waves. There are many different strategies to mitigate UHI, including cooler roofs and pavements, increasing vegetation area, or changing the urban geometry $[3,4]$. Among the most efficient mitigation strategies, it is worth mentioning the use of roofs with high albedo (white roofs), which may halve the total sensible heat flux [5].

On the other hand, increasing urbanization across the world leads to increasing local demand for energy, which can be addressed, at least partially, by solar energy generation on rooftops and facades of the buildings themselves [3,6]. However, since PV panels are specifically designed to have a low albedo (as they can only convert to electricity the absorbed irradiation), large-scale deployment of urban PV installations has the potential to increase the absorption of solar radiation, adding to the solar energy loading of a city, thus increasing the UHI effect.

Studies of the impact of utility-scale photovoltaic plants on local climate have consistently shown a warming effect. Ref. [7] monitored sites representing the traditional built urban environment (parking lot) and the transformation from a natural system (undeveloped desert) to a 1 MW PV power plant, both within the boundaries of the University of Arizona Science and Technology Park Solar Zone, in the USA. They found that temperatures over the PV plants were regularly $3-4{ }^{\circ} \mathrm{C}$ warmer than wildlands at night. Also in Arizona [8] reported an average daily maximum air temperature at $1.5 \mathrm{~m}$ (the height relevant for human comfort) at the PV array was $1.3^{\circ} \mathrm{C}$ warmer than the reference (i.e., non-PV) site, whereas no significant difference in nocturnal air temperature was observed. Ref. [9] observed monthly average 2-m air temperature in the solar farm in the Gobi Desert, China, is 5\% higher (measured in ${ }^{\circ} \mathrm{C}$ ) than that in the region without PV. Ref. [10] measured daytime heating and night-time cooling of the surfaces of PV panels in a solar power plant in a barren area of Gonghe, China. The average 
heating was $3.8^{\circ} \mathrm{C}$. They showed that cooling of the land surface associated with the PV plant $\left(-4{ }^{\circ} \mathrm{C}\right)$ is related to the physical shading by the PV panels.

The impact of PV in the built environment has only been studied by modeling and simulation, due to the lack of urban sites with a large enough deployment of photovoltaics that could significantly impact the local microclimate. This absence of experimental studies shows that there is a clear need for air and surface temperature monitoring of urban PV installations to assess their effect on urban climate.

One exception to this lack of experimental studies is [11], who studied the effect of a PV shading structure on the ambient temperature in Phoenix, Arizona. They have measured an $80 \%$ increase in the sensible heat flux for the PV system and registered a $+12{ }^{\circ} \mathrm{C}$ temperature increase when compared to a non-PV reflective shading structure.

Ref. [12] estimated that the impact of the large-scale installation of PV systems on the building canopy temperature would be negligible in Tokyo if PV systems are installed on black roofs, with a decrease in energy consumption between $2 \%$ and 10\%. Ref. [13] studied the UHI impact of solar panels in Los Angeles by considering an effective albedo accounting for the albedo and solar conversion efficiency. Critically, this approximation does not consider the lower albedo of PV modules when compared to standard roofing materials. It leads to $0.2{ }^{\circ} \mathrm{C}$ cooling for large scale deployment of solar PV for a wide range of PV efficiencies, between 10 and 30\%. The cooling effect is lower than but comparable to the UHI impact of extensive implementation of highly reflective roofs and pavements.

Ref. [14] studied the impact of both solar thermal and photovoltaic modules in Paris using the SURFEX modeling software coupled with a one-dimensional heat exchange balance on rooftops. They consider solar modules as an add-on to the building, shadowing the standard roof; therefore, the irradiation reaching the PV-covered rooftop is no longer the solar shortwave irradiation but the downwards longwave emission of the solar module. This approach leads to a strong decrease in energy consumption for air conditioning $(12 \%)$ and a slight decrease in UHI $\left(0.2-0.3^{\circ} \mathrm{C}\right)$ in the summer months. Following on the work of Masson [15] simulated the effect of PV roofs for a 10-day clear sky extreme heat period over the Phoenix and Tucson metropolitan areas, observing an $8-11 \%$ reduction in cooling energy demand with 100\% rooftop coverage with PV panels.

The impact of PV facades in urban microclimate has been less explored. Ref. [16] have developed an integrated model for both rooftops and facades including four different sub-models: (i) a PV thermal model, (ii) a PV electrical performance model, (iii) a building energy consumption model and (iv) an urban canyon energy budget model, forced with temperature, wind speed and solar radiation above the roof level. They have shown that, for a summer day in Tianjin, China, PV modules installed with a ventilated air gap $(0.20 \mathrm{~m})$ significantly change the building surface temperature during daytime (stronger effect on rooftops than facades, $-9.4{ }^{\circ} \mathrm{C}$ and $-4.6{ }^{\circ} \mathrm{C}$, respectively) but there is little change in the air temperature in the urban canyon even for massive deployment of PV on rooftops and facades. The reference roof was assumed to have a low albedo (0.1); simulations with a more common roof albedo of 0.3 showed that "the differences between sensible heat fluxes between PV roof and normal roof are very slight".

Ref. [17] used computational fluid dynamics coupled with a mesoscale numerical weather prediction tool (WRF) and a one-dimensional heat conduction model for a study area in Osaka, Japan. As in [16], they assumed low albedos of the reference roof and wall (only 0.1). They estimated increasing temperatures for roofs and walls directly exposed to irradiation $\left(0.4^{\circ} \mathrm{C}\right.$ and 0.8 to $2.6^{\circ} \mathrm{C}$, respectively) but, on average, decreasing temperatures during daytime $\left(2.1^{\circ} \mathrm{C}\right.$ and $\left.0.8^{\circ} \mathrm{C}\right)$ and nighttime $\left(1.4^{\circ} \mathrm{C}\right.$ and $4.3^{\circ} \mathrm{C}$ ), an effect they attribute to the lower heat capacity of PV modules compared with regular building materials. The effect on air temperature (at $1.5 \mathrm{~m}$ ) is milder, with an average cooling effect of $0.1^{\circ} \mathrm{C}$ with a maximum temperature difference in the evening $\left(0.4^{\circ} \mathrm{C}\right)$.

In summary, one is drawn to conclude that PV deployment leads to daytime warming due to its lower albedo and nighttime cooling due to its lower heat capacity. In the built environment, these effects seem to be relevant for surface temperatures (rooftops and walls) but almost unnoticeable for air temperature. The reported (small) decreases in average air temperature are always associated with the 
improvement of the building energy performance with the installation of photovoltaics. PV is assumed to reduce the building heat load, either by considering its shading on the building (for a building-applied PV configuration, with standard PV modules mounted on the top of an existing rooftop, as in [14]), or improved thermal insulation due to the PV ventilation gap (for a building-integrated PV configuration, with an architectural integration of the PV modules in the building, as in [16]). The associated decrease in energy demand (less energy to cool down the building) results in lower "anthropogenic waste heat" and, therefore, in all the cited literature, PV in buildings leads to a decrease in urban temperature due to lower cooling needs in buildings. This effect could also be achieved by changing the thermal characteristics of buildings (e.g., using materials with lower thermal conductivity), a trend that is already set by many building codes across the globe [18] and, therefore, should not be attributed to the installation of the PV modules alone. It is, therefore, convenient to assess the impact of PV in the urban microclimate regardless of its impact on local energy consumption.

This work presents a steady-state model for one- and two-dimensional irradiance balance in buildings to assess the impact of high penetration of photovoltaics on the urban climate. Sections 2 and 3 present the analytical models for PV on rooftops and facades, respectively. Section 4 presents results for typical settings, Section 5 discusses the implications of the results, and Section 6 concludes.

\section{One Dimensional Model (Rooftops)}

A rooftop with albedo $\alpha_{r}$ receiving irradiance $I$, reflects $\alpha_{r} I$. The remainder will be absorbed, heating the building. Figure 1 (left) shows the schematic representation of the irradiance balance on the rooftop surface. Notice that we are assuming a one-dimensional vertical energy balance, and therefore the inclination of the roof is neglected. This is a reasonable assumption if the inclination is not too steep (due to the variation of the albedo with the angle of incidence) and there are no neighboring tall buildings that could reduce the sky view factor of the roof.
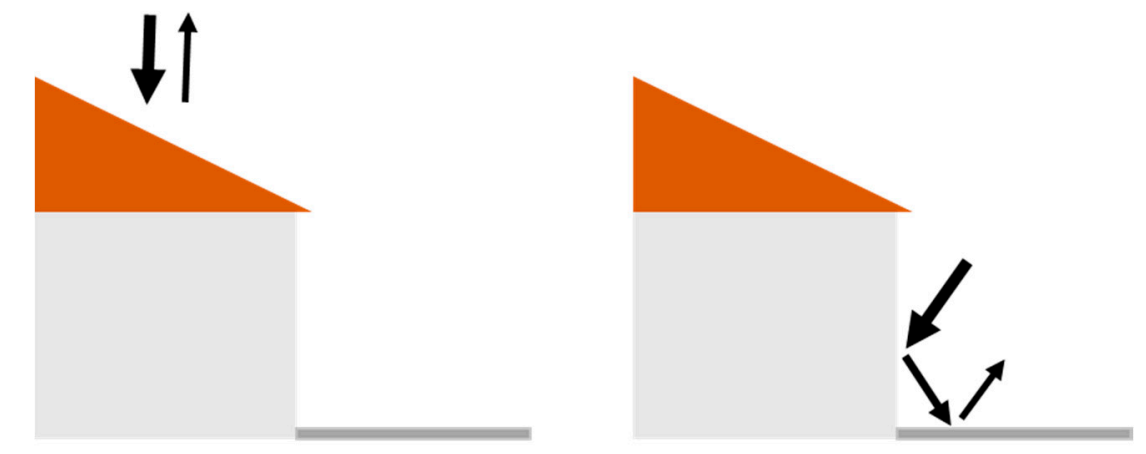

Figure 1. Schematic of irradiance balance of 1D model for rooftops (left) and 2D model for facades (right).

In these conditions, the irradiance balance on the rooftop is simply the difference between the incoming $\left(G_{\text {in }}\right)$ and outgoing $\left(G_{\text {out }}\right)$ irradiance:

$$
\left(G_{\text {in }}-G_{\text {out }}\right)_{r}=I-\alpha_{r} I
$$

If the rooftop is covered with PV modules with a different albedo, $\alpha_{P V}$, the reflected irradiance, will be $\alpha_{P V} I$. However, part of the absorbed irradiance will be converted to electricity at the PV module. The remainder will contribute to the heating of the building. The irradiance balance for a solar rooftop is

$$
\left(G_{\text {in }}-G_{\text {out }}\right)_{P V}=I-\eta\left(1-\alpha_{P V}\right) I-\alpha_{P V} I
$$

where $\eta$ is the efficiency of the PV conversion, typically below $20 \%$.

The difference between the two conditions, $\Delta I$, is a measure of the impact of PV roofs on the urban climate. If positive, PV rooftops will contribute to urban heating. If negative, solar roofs would be a mitigation strategy for addressing the urban heat island effect. 
Using the equations above, we can write

$$
\begin{gathered}
\Delta I=\left(G_{\text {in }}-G_{\text {out }}\right)_{P V}-\left(G_{\text {in }}-G_{\text {out }}\right)_{r} \\
\Delta I=I-\eta\left(1-\alpha_{P V}\right) I-\alpha_{P V} I-I+\alpha_{r} I \\
U H I_{r} \equiv \frac{\Delta I}{I}=\left(\alpha_{r}-\alpha_{P V}\right)-\eta\left(1-\alpha_{P V}\right)
\end{gathered}
$$

The relative impact of the solar modules on the climate, $\Delta I / I$, is henceforth named UHI signal for roofs and denoted $U H I_{r}$.

This result shows that the UHI signal decreases with the PV conversion efficiency. It is interesting to note that setting $U H I_{r}=0$ leads to

$$
\eta_{r, 0}=\frac{\alpha_{r}-\alpha_{P V}}{1-\alpha_{P V}}
$$

where $\eta_{r, 0}$ is the threshold PV efficiency for rooftop PV modules above which the UHI signal is negative, and therefore for which PV contributes to urban cooling.

\section{Two-Dimensional Model (Facades)}

For the analysis of PV on facades, one must consider the effect of the incidence angle and the albedo of the street (Figure 1, right). The irradiance balance for a standard facade is

$$
\left(G_{\text {in }}-G_{\text {out }}\right)_{w}=I-\alpha_{w} \alpha_{g}(I \cos \theta)
$$

where $\alpha_{w}$ and $\alpha_{g}$ are the albedo of the wall and ground, respectively. The zenith angle $\theta$ is measured from the vertical $(\theta=0$ for vertical) and, therefore, $I \cos \theta$ is the vertical component of the incoming irradiance on the vertical surface.

For a PV facade, the irradiance balance will include one extra term, corresponding to the irradiance converted to electricity, hence proportional to the horizontal component of irradiation, I $\sin \theta$.

$$
\left(G_{\text {in }}-G_{\text {out }}\right)_{P V}=I-\eta\left(1-\alpha_{P V}\right) I \sin \theta-\alpha_{P V} \alpha_{g} I \cos \theta
$$

The relative effect of PV facades is then

$$
\begin{gathered}
\Delta I=\left(G_{\text {in }}-G_{\text {out }}\right)_{P V}-\left(G_{\text {in }}-G_{\text {out }}\right)_{w} \\
\Delta I=I-\eta\left(1-\alpha_{P V}\right) I \sin \theta-\alpha_{P V} \alpha_{g} I \cos \theta-I+\alpha_{w} \alpha_{g} I \cos \theta \\
\frac{\Delta I}{I}=\left(\alpha_{w}-\alpha_{P V}\right) \alpha_{g} \cos \theta-\eta\left(1-\alpha_{P V}\right) \sin \theta
\end{gathered}
$$

Noting that the effective area of the facade as seen from the sunshine direction will also depend on the zenith angle (i.e., the area of the facades is more relevant for the city irradiance balance when the sun is lower in the sky, i.e., higher $\theta$ ) one may consider the PV wall impact on the urban heat island to be affected by a factor of $\sin \theta$. Thus, the effect of walls on the UHI signal vanishes for zenith incidence.

$$
U H I_{w} \equiv \frac{\Delta I}{I} \sin \theta=\left(\alpha_{w}-\alpha_{P V}\right) \alpha_{g} \cos \theta \sin \theta-\eta\left(1-\alpha_{P V}\right) \sin ^{2} \theta
$$

The threshold conversion efficiency $\eta_{w, 0}$ for PV facades above which the UHI is negative is

$$
\eta_{w, 0}=\frac{\alpha_{w}-\alpha_{P V}}{1-\alpha_{P V}} \alpha_{g} \cot \theta
$$


hence, very much dependent on the incidence of irradiation. Despite the factor due to the ground albedo, for the relevant zenith angles (low $\theta$, hence high $\cot \theta$ ) the threshold efficiency for facades is in general higher than for rooftops.

The zenith angle depends on the location and the time of the year. It is

$$
\cos \theta=\sin \delta \sin \phi+\cos \delta \cos \phi \cos \omega
$$

where $\delta$ is the declination, $\phi$ is the latitude, and $\omega$ is the hour angle, equal to zero at noon.

\section{Results}

Using Equation (3) for the irradiance balance on rooftops, Figure 2 (red line) plots the UHI signal $(\Delta I / I)$ as a function of the PV efficiency, for typical values of albedo $\left(\alpha_{r}=30 \% ; \alpha_{P V}=10 \%\right)$. These results show that, in these conditions, solar rooftops contribute positively to urban heating for efficiencies lower than $\eta_{0}=22 \%$. This result is less stringent than the result of [19] which estimated that the heat released to the town will decrease as soon as the PV conversion efficiency is larger than the average albedo of the city. Nevertheless, one can see that for typical efficiencies $(>16 \%)$ the impact is below $5 \%$.

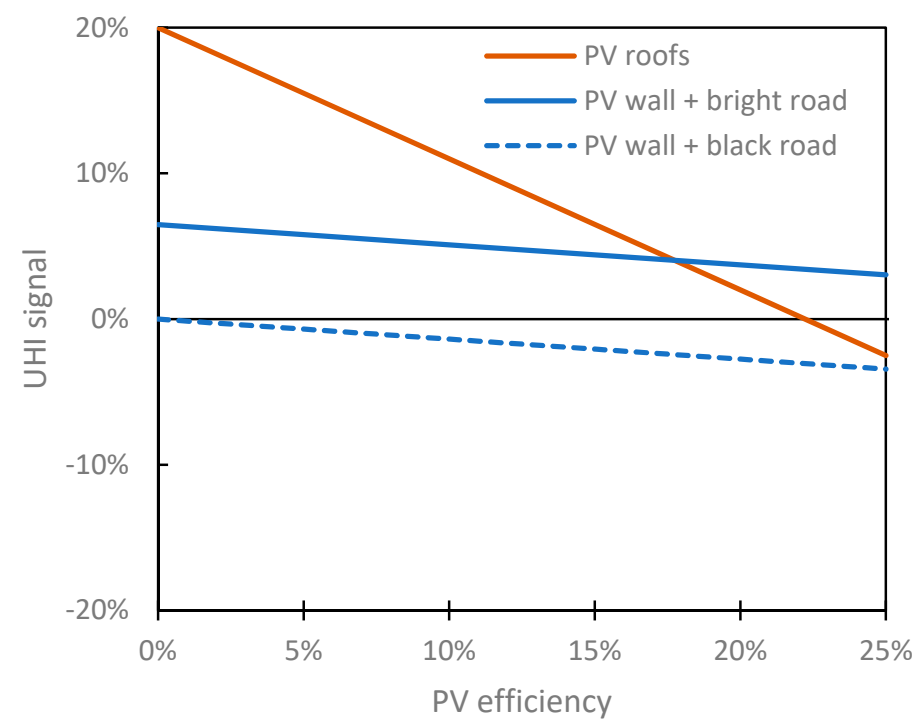

Figure 2. Effect of PV efficiency (horizontal axis) on the relative irradiance balance, the UHI signal, for rooftops (red line) and facades (blue line). The solid line refers to a bright road and the dashed line refers to a dark road. Results for $\alpha_{r}=30 \% ; \alpha_{P V}=10 \% ; \alpha_{w}=70 \% ; \theta=23 ; \alpha_{g}=30 \%$ (bright road) or $\alpha_{g}=0 \%$ (dark road).

Noting that the conversion efficiency decreases with module temperature, which is typically about $-0.3 \% /{ }^{\circ} \mathrm{C}$ for the crystalline silicon technology [20], these results suggest that the UHI signal will be further enhanced for hot climates.

For PV facades, using Equation (8), the UHI signal is rather dependent on the reflectivity properties of the ground. Figure 2 (blue lines) shows the relative effect of the PV facade for $\theta=23^{\circ}$ (its maximum value) considering typical values of albedo $\left(\alpha_{w}=70 \% ; \alpha_{P V}=10 \%\right)$. The ground albedo for a bright road is $\alpha_{g}=30 \%$ (solid line) and it is zero for the dark road (dashed line).

From Equation (9), considering $\theta=23^{\circ}$ and the quoted typical values for the albedo of the walls, PV modules, and grounds, the threshold conversion efficiency for facades is $\eta_{w, 0}=47 \%$.

One can note that, for the extreme case of a dark road, the impact of the PV facades is always cooling. This is to be expected, since a PV wall will reduce the irradiation reflected towards the ground (more irradiation is absorbed by the walls, either for electricity generation or heating). For a bright road, there is a small contribution to urban heating. 
The incidence angle is also a critical parameter. Figure 3 shows the UHI signal of PV walls (with a typical efficiency of 20\%). We can observe that for low zenith angles (near-vertical incidence) there is no relevant effect because walls are not relevant to the city irradiance balance. For zenith angles below $45^{\circ}$, the effect of the PV walls depends on the reflectivity of the ground: heating for high ground albedo and cooling for low ground albedo. For higher zenith angles $\left(>45^{\circ}\right)$, the effect is always cooling. Nevertheless, the magnitude of the UHI signal is always small (below $3.7 \%$ ).

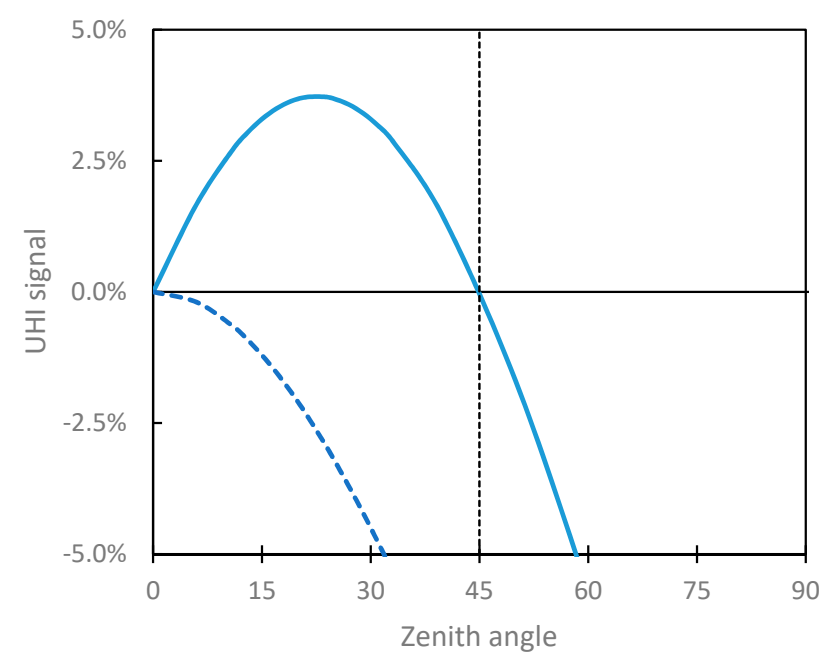

Figure 3. Irradiance balance or UHI signal for PV facades for the scenarios with a bright road (solid line) and a dark road (dashed line) as a function of zenith nce angle for $\alpha_{r}=30 \% ; \alpha_{P V}=10 \% ; \alpha_{w}=70 \%$; $\alpha_{g}=30 \%$ (bright road) or $\alpha_{g}=0 \%$ (dark road). The dotted vertical line indicates $\theta=45$. PV efficiency assumed: $20 \%$.

Considering that the urban heat island effect is more relevant in the summer, one can plot the UHI signal of PV walls as a function of latitude, for noon of the summer solstice when declination is maximum (Figure 4). For high ground albedo, PV walls lead to heating for latitudes below the Artic (and the Antarctic) circle, whilst, for low ground albedo, there is always a cooling effect. The effect is maximum at the equator and mid-latitudes, vanishing around the Tropic of Cancer (and Capricorn) due to vertical incidence at noon of the summer solstice.

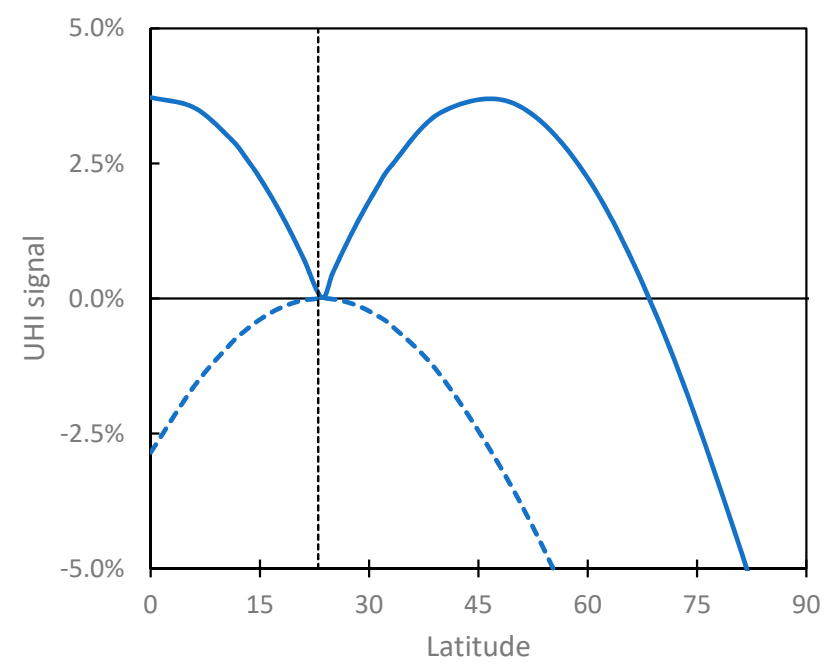

Figure 4. Irradiance balance or UHI signal for PV facades for the scenarios with a bright road (solid line) and a dark road (dashed line) as a function of latitude for $\alpha_{r}=30 \% ; \alpha_{P V}=10 \% ; \alpha_{w}=70 \% ; \alpha_{g}=30 \%$ (bright road) or $\alpha_{g}=0 \%$ (dark road). The dotted vertical line indicates $\phi=23$. PV efficiency assumed: $20 \%$. 
We can also plot the effect of the PV walls throughout the year. Figure 5 shows the relative effect of PV facades for the equator, at noon. We can observe that the UHI signal of the PV walls is accentuated at the solstices, vanishing at the equinoxes. Nevertheless, as shown before, it is always relatively small.

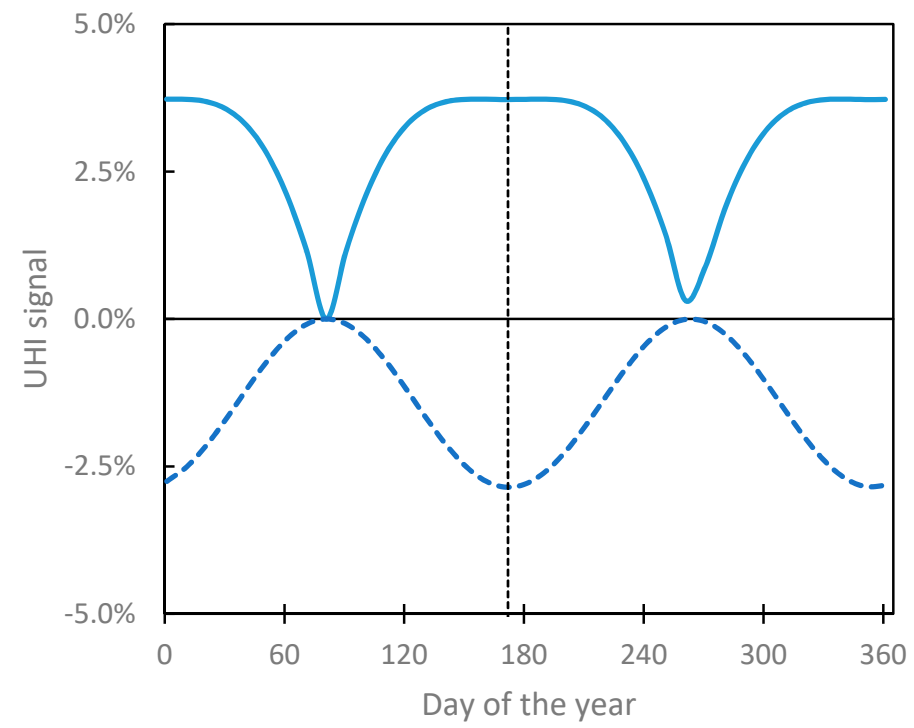

Figure 5. Irradiance balance or UHI signal for PV facades for the scenarios with a bright road (solid line) and a dark road (dashed line) as a function of the day of the year for $\alpha_{r}=30 \% ; \alpha_{P V}=10 \% ; \alpha_{w}=70 \%$; $\alpha_{g}=30 \%$ (bright road) or $\alpha_{g}=0 \%$ (dark road). The dotted vertical line indicates the summer solstice. PV efficiency assumed: $20 \%$.

\section{Discussion}

This is a very simple model with significant approximations. Since the model does not account for longwave emission from warmer surfaces, the estimated heating (cooling) effect is expected to be somewhat mitigated by increasing (decreasing) thermal emission. For vertical surfaces, the effect is perhaps not very significant for dense urban areas due to the low sky view factors. For rooftops, this is expected to be a relevant correction.

For clarity of the argument, the discussion above considers typical values for the rooftop, wall, and ground albedos. To assess the effect of this somewhat arbitrary choice, Figure 6 presents a sensitivity analysis of the UHI signal to varying albedos of rooftops, walls, and ground. The effect of changing the PV modules' albedo is also shown.

One can observe that increasing the albedo of the buildings and its surroundings enhances the UHI signal since the low albedo of PV modules has a stronger absorbing effect. Thus, the deployment of PV modules in a brighter city leads to a stronger heating effect. The effect of varying the wall and ground albedos is less pronounced than that of the rooftops ( -3 to $8 \%$ versus -22 to $20 \%$, respectively, considering a wide albedo range), reinforcing previous results on the role of white roofs to mitigate the urban heat island effect.

Increasing the reflectivity of the PV modules has the opposite effect. In this sensitivity analysis, it is considered that the conversion efficiency of the PV modules decreases linearly as its albedo increases; thus, a dark PV module (10\% albedo) is assumed to be $20 \%$ efficient while a bright PV module (50\% albedo) has half its efficiency. This is a realistic assumption, since, in the brighter PV module, fewer photons will penetrate the material. A practical implementation of this approach would be the "white PV module" concept, which reflects visible light and only converts to electricity the infrared part of the solar spectrum [21]. Figure 6 shows that large scale deployment of white PV modules on rooftops could reduce urban heating significantly, the impact on facades being much less pronounced. 

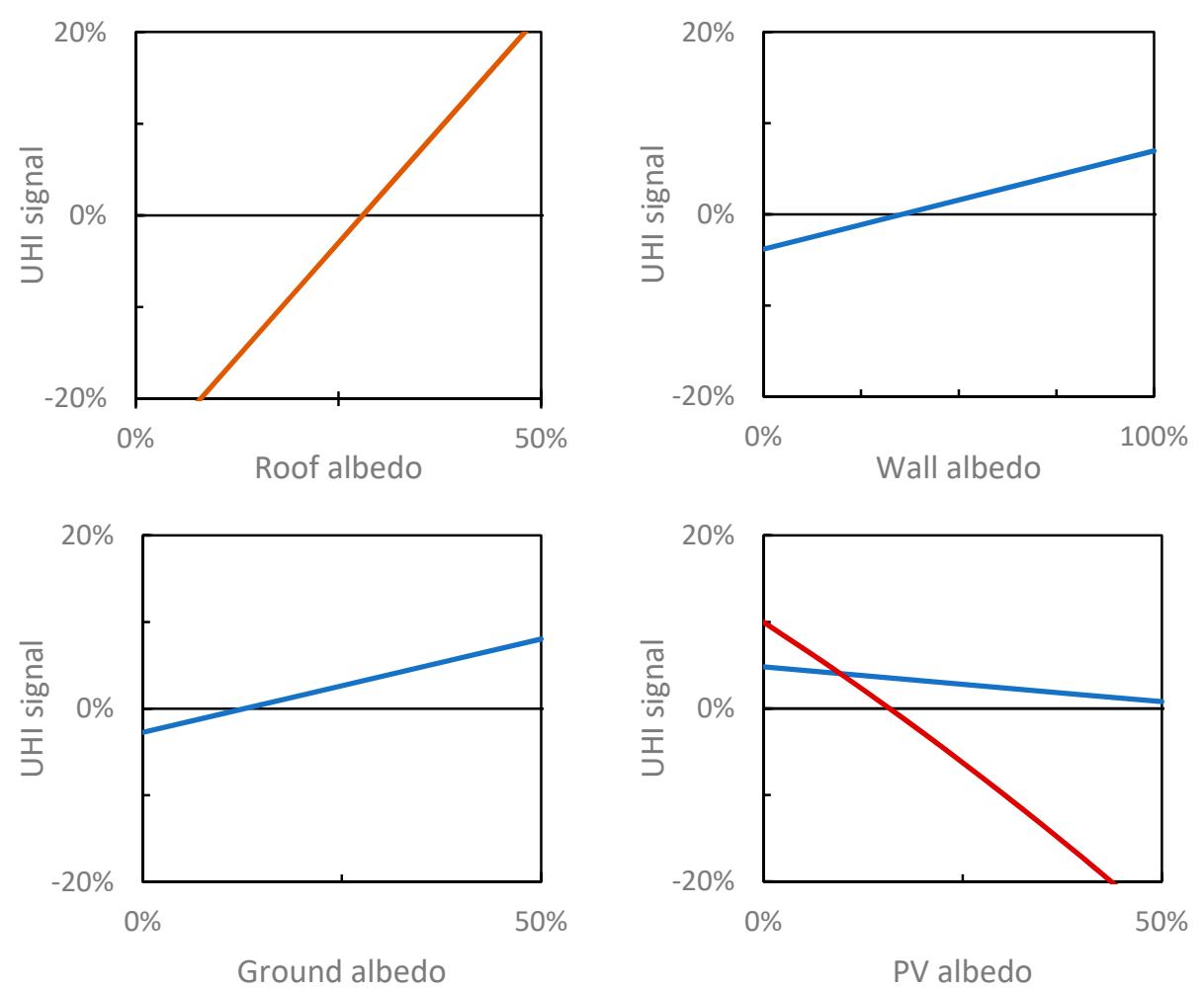

Figure 6. Sensitivity analysis for the relative irradiance balance, the UHI signal, for rooftops (red line) and facades (blue line) to the rooftop albedo (left), wall albedo (center) and ground albedo (right). Reference case: $\eta=20 \% ; \alpha_{P V}=10 \% ; \alpha_{r}=30 \% ; \alpha_{w}=70 \% ; \alpha_{g}=30 \%$.

The model only considers direct irradiation. Diffuse irradiation is mostly isotropic, and therefore one would expect that it would encompass an averaging effect over incidence angle. Given the results shown in Figure 3, considering diffuse irradiation would possibly lead to a slight shift towards negative UHI signals, reducing the heating impact of PV during the summer period. This effect is not expected to be very significant since high diffuse fraction is typically associated with cloudy skies, hence, when there is lower irradiation.

The model also does not include diffusive non-specular reflection on rooftops, walls, or the ground. The effect is not expected to be particularly relevant for rooftops, but in facades it might reduce heating since the diffuse reflection on a white wall will halve the downwards reflected irradiation as half of the reflected will be "sent" upwards. In general, PV modules feature higher specular reflectivity than regular wall paint and, therefore, one would expect an increased impact on urban climate.

All the results shown above refer to noon when incident power is maximum. However, the urban climate is a dynamic problem, and the thermal inertia of buildings and pavements is a critical factor for the urban heat island. In general, cities hold heat longer than rural areas (higher thermal inertia), and a stronger urban heat island signal is often associated with warmer temperatures in the evening. PV modules have much lower thermal inertia than other regular building materials, and, therefore, they are expected to cool down faster, hence reducing the ambient temperature in the late afternoon and evening, as has been described by [16].

As discussed in the introductory section, it is also important to underline that the model is not considering changes in the building energy performance due to the integration of PV modules in their rooftop or facades. It is customary, and appropriate, to install PV modules with a spacing behind for cooling by natural ventilation since their efficiency decreases for higher temperatures. This air space will contribute to increased thermal insulation between the building and the outside environment, and, therefore, to an increase in temperature of the (outer layer of the) wall will not necessarily mean increased temperature inside the building. Of course, the same effect could be achieved by improving 
the thermal insulation of the wall materials, and, therefore, this effect should not be considered a direct impact of the PV modules themselves.

\section{Conclusions}

A steady-state model for short wave irradiance balance for rooftops and facades was developed to assess the impact of high penetration of photovoltaics on the urban climate. Despite its limitations, the results of this simple model are clear enough to illustrate the general impact of strong PV penetration in urban climate.

We have shown that, albeit small, with current PV conversion efficiencies, photovoltaics on rooftops are expected to have a heating effect on the urban environment. Higher efficiencies could lead to a cooling effect.

The impact of PV facades on the urban climate is shown to be always small. Its signal (heating or cooling) depends critically on the reflectivity of the environment, in particular, the ground albedo: for highly reflective roads, PV walls lead to heating, whilst for darker roads, PV may lead to city cooling. The effect is higher for the equator and mid-latitudes during the summer months, vanishing at the equinoxes. These regions, which typically feature warmer climates, are expected to have a slightly enhanced UHI signal due to lower PV conversion efficiency at higher ambient temperatures.

The magnitude of the impact of PV on the urban microclimate, both for rooftops and facades, is always small, and, therefore, photovoltaics ought not to be considered a mitigation strategy for urban heat island.

Acknowledgments: This research was funded by FCT - Fundação para a Ciência e Tecnologia, grant number UID/GEO/50019/2019.

Conflicts of Interest: The author declares no conflict of interest.

\section{References}

1. Oke, T.R. The energetic basis of the urban heat island. Q. J. R. Meteorol. Soc. 1982, 108, 1-24. [CrossRef]

2. Patz, J.A.; Campbell-Lendrum, D.; Holloway, T.; Foley, J.A. Impact of regional climate change on human health. Nature 2005, 438, 310-317. [CrossRef] [PubMed]

3. Bódis, K.; Kougias, I.; Jäger-Waldau, A.; Taylor, N.; Szabó, S. A high-resolution geospatial assessment of the rooftop solar photovoltaic potential in the European Union. Renew. Sustain. Energy Rev. 2019, 114, 109309. [CrossRef]

4. Gago, E.J.; Roldan, J.; Pacheco-Torres, R.; Ordóñez, J. The city and urban heat islands: A review of strategies to mitigate adverse effects. Renew. Sustain. Energy Rev. 2013, 25, 749-758. [CrossRef]

5. Scherba, A.; Sailor, D.J.; Rosenstiel, T.N.; Wamser, C.C. Modeling impacts of roof reflectivity, integrated photovoltaic panels and green roof systems on sensible heat flux into the urban environment. Build. Environ. 2011, 46, 2542-2551. [CrossRef]

6. Redweik, P.; Catita, C.; Brito, M. Solar energy potential on roofs and facades in an urban landscape. Sol. Energy 2013, 97, 332-341. [CrossRef]

7. Barron-Gafford, G.A.; Minor, R.L.; Allen, N.A.; Cronin, A.D.; Brooks, A.E.; Pavao-Zuckerman, M.A. The Photovoltaic Heat Island Effect: Larger solar power plants increase local temperatures. Sci. Rep. 2016, 6, 35070. [CrossRef] [PubMed]

8. Broadbent, A.M.; Krayenhoff, E.S.; Georgescu, M.; Sailor, D.J. The Observed Effects of Utility-Scale Photovoltaics on Near-Surface Air Temperature and Energy Balance. J. Appl. Meteorol. Climatol. 2019, 58, 989-1006. [CrossRef]

9. Yang, L.; Gao, X.; Lv, F; Hui, X.; Ma, L.; Hou, X. Study on the local climatic effects of large photovoltaic solar farms in desert areas. Sol. Energy 2017, 144, 244-253. [CrossRef]

10. Chang, R.; Shen, Y.; Luo, Y.; Wang, B.; Yang, Z.; Guo, P. Observed surface radiation and temperature impacts from the large-scale deployment of photovoltaics in the barren area of Gonghe, China. Renew. Energy 2018, 118, 131-137. [CrossRef] 
11. Pham, J.V.; Baniassadi, A.; Brown, K.E.; Heusinger, J.; Sailor, D.J. Comparing photovoltaic and reflective shade surfaces in the urban environment: Effects on surface sensible heat flux and pedestrian thermal comfort. Urban Clim. 2019, 29, 100500. [CrossRef]

12. Genchi, Y.; Ishisaki, M.; Ohashi, Y.; Kikegawa, Y.; Takahashi, H.; Inaba, A. Impacts of Large-Scale Photovoltaic Panel Installation on the Heat Island Effect in Tokyo. In Proceedings of the Fifth Conference on the Urban Climate, Lodz, Poland, 1-5 September 2003; pp. 1-4.

13. Taha, H. The potential for air-temperature impact from large-scale deployment of solar photovoltaic arrays in urban areas. Sol. Energy 2013, 91, 358-367. [CrossRef]

14. Masson, V.; Bonhomme, M.; Salagnac, J.-L.; Briottet, X.; Lemonsu, A. Solar panels reduce both global warming and urban heat island. Front. Environ. Sci. 2014, 2. [CrossRef]

15. Salamanca, F.; Georgescu, M.; Mahalov, A.; Moustaoui, M.; Martilli, A. Citywide Impacts of Cool Roof and Rooftop Solar Photovoltaic Deployment on Near-Surface Air Temperature and Cooling Energy Demand. Boundary-Layer Meteorol. 2016, 161, 203-221. [CrossRef]

16. Tian, W.; Wang, Y.; Ren, J.; Zhu, L. Effect of urban climate on building integrated photovoltaics performance. Energy Convers. Manag. 2007, 48, 1-8. [CrossRef]

17. Cortes, A.; Murashita, Y.; Matsuo, T.; Kondo, A.; Shimadera, H.; Inoue, Y. Numerical evaluation of the effect of photovoltaic cell installation on urban thermal environment. Sustain. Cities Soc. 2015, 19, $250-258$. [CrossRef]

18. Papadopoulos, A.M. Forty years of regulations on the thermal performance of the building envelope in Europe: Achievements, perspectives and challenges. Energy Build. 2016, 127, 942-952. [CrossRef]

19. Roulet, C.-A. Solar energy and global heat balance of a city. Sol. Energy 2001, 70, 255-261. [CrossRef]

20. Skoplaki, E.; Palyvos, J.A. On the temperature dependence of photovoltaic module electrical performance: A review of efficiency/power correlations. Sol. Energy 2009, 83, 614-624. [CrossRef]

21. Escarre, J.; Li, H.Y.; Sansonnens, L.; Galliano, F.; Cattaneo, G.; Heinstein, P.; Nicolay, S.; Bailat, J.; Eberhard, S.; Ballif, C.; et al. When PV modules are becoming real building elements: White solar module, a revolution for BIPV. In Proceedings of the 2015 IEEE 42nd Photovoltaic Specialist Conference (PVSC), New Orleans, LA, USA, 14-19 June 2015. [CrossRef]

(C) 2020 by the author. Licensee MDPI, Basel, Switzerland. This article is an open access article distributed under the terms and conditions of the Creative Commons Attribution (CC BY) license (http://creativecommons.org/licenses/by/4.0/). 